\title{
Resposta de fase aguda, subnutrição e estado nutricional do ferro em adultos com AIDS
}

\author{
Iron status, malnutrition and acute phase \\ response in HIV-positive patients
}

\author{
Jacqueline Pontes Monteiro, Daniel Ferreira da Cunha, \\ Selma Freire de Carvalho da Cunha, Vitorino Modesto dos Santos, \\ Mário León Silva-Vergara, Dalmo Correia e Maria de Lourdes Pires Bianchi
}

Resumo Foram comparados o estado nutricional e parâmetros do metabolismo do ferro de adultos HIV-positivos, com ou sem resposta de fase aguda (RFA). Adultos HIV-positivos $(n=29)$ submeteram-se a antropometria, recordatório alimentar e determinação sérica de albumina, proteína C reativa (PCR), ferritina e capacidade total de ligação do ferro (CTLF), além de creatinina urinária. Infecção mais $P C R>7 \mathrm{mg} /$ dl foram critérios de positividade da RFA. Índice de massa corporal (IMC < 18,5kg/m²) e índice creatinina-altura (ICA $<70 \%)$ definiram subnutrição. Subnutrição (77,8 vs $40 \%)$ e tuberculose pulmonar (44,4 vs $9,5 \%)$ foram mais freqüentes nos pacientes RFA-positivos, que também apresentaram menores níveis de albumina $3,7 \pm 0,9$ vs $4,3 \pm 0,9 \mathrm{~g} / \mathrm{dl})$, CTLF (165,8 $\pm 110,7$ vs $265,9 \pm 74,6 \mathrm{mg} / \mathrm{dl})$ e hemoglobina $(10,5 \pm 1,8$ vs $12,6 \pm$ $2,3 \mathrm{~g} / \mathrm{dl}$ ). A ingestão de ferro foi adequada e similar entre RFA-positivos e RFA-negativos, o mesmo ocorrendo, respectivamente, quanto à ferritina sérica (mediana; variação, 568; 45,3-1814 vs 246; 18,4-1577ng/ml). Pacientes HIV-positivos com resposta de fase aguda são nutricionalmente mais comprometidos e têm anemia que parece não depender da ingestão recente de ferro.

Palavras-chaves: Resposta de fase aguda. Ferro. AIDS. Estado nutricional. Subnutrição protéicoenergética.

\begin{abstract}
Nutritional status and some iron metabolism parameters of acute phase response (APR) positive and APR-negative AIDS patients were studied. Twenty-nine AIDS patients were submitted to $24 \mathrm{~h}$ food intake recall, anthropometry, and albumin, C-reactive protein (CRP), hemoglobin, ferritin, and total iron binding capacity (TIBC) measurements. Infection plus serum $C R P>7 \mathrm{mg} / \mathrm{dl}$ were criteria for APR presence. Protein-energy malnutrition (PEM) was ascertained by body mass index (BMI) lower than $18.5 \mathrm{~kg} / \mathrm{m}^{2}$ and height-creatinine index $(\mathrm{HCl}<70 \%)$. PEM (77.8 vs $40 \%$ ) and pulmonary tuberculosis (44.4 vs 9.5\%) were more frequent in APR-positive patients, which also had lower serum albumin $(3.7 \pm 0.9 \mathrm{vs} 4.3 \pm 0.9 \mathrm{~g} / \mathrm{dl})$, TIBC $(165.8 \pm 110.7 \mathrm{vs}$ $265.9 \pm 74.6 \mathrm{mg} / \mathrm{dl})$ and blood hemoglobin $(10.5 \pm 1.8 \mathrm{vs} 12.6 \pm 2.3 \mathrm{~g} / \mathrm{dl})$. Iron intake was similar between groups; however, serum ferritin levels (median, range) were higher among APR-positive (568, 45.3-1814 vs 246, 18.4-1577ng/ml) patients. HIV-positive adults with systemic response to invading pathogens showed worse nutritional status than those APR-negative. In APR-positive AIDS patients, anemia appears to be unrelated to recent iron intake.
\end{abstract}

Key-words: Acute phase response. Iron status. AIDS. Protein-energy malnutrition.

\footnotetext{
Serviço de Suporte Metabólico-Nutricional da Disciplina de Nutrologia do Departamento de Clínica Médica da Faculdade de Medicina do Triângulo Mineiro, Uberaba, MG e Faculdade de Farmácia de Ribeirão Preto/USP, Ribeirão Preto, SP.

Apoio financeiro: Fundação de Ensino e Pesquisa de Uberaba (FUNEPU).

Endereço para correspondência: Prof. Daniel Ferreira da Cunha. Disciplina de Nutrologia/Departamento de Clínica Médica/HE/FMTM. Av. Getúlio Guarita s/n, 38025-440 Uberaba, MG, Brasil.

Telefax: 5534 318-5335.

e-mail: dfcnutro@mednet.com.br

Recebido para publicação em 28/1/99.
} 
A subnutrição protéico-energética (SPE) ocorre em alta porcentagem de adultos infectados pelo HIV-1 (human immunodeficiency virus), o que piora o comprometimento imunológico e aumenta morbidade e mortalidade ${ }^{12}$. Em doenças crônicas que cursam com anorexia há ingestão insuficiente de alimentos e balanço energético negativo, processos que se acompanham de diminuição progressiva das reservas corporais de gordura e de massa muscular, resultando em emagrecimento acentuado, que caracteriza - marasmo. Quadros agudos de edema hipoalbuminêmico, típicos da subnutrição protéica observada em crianças (kwashiorkor) também podem ocorrer em adultos, sendo geralmente desencadeados por infecções, trauma ou cirurgia ${ }^{15}$.

A resposta sistêmica do hospedeiro às infecções é denominada resposta de fase aguda (RFA), sendo constituída por alterações neurohumorais, imunológicas e metabólicas, mediadas, entre outros fatores, por interleucinas produzidas pelo sistema fagocítico-mononuclear ${ }^{6}{ }^{17}$. Além da anorexia e do aumento do gasto energético, associado ou não à febre, ocorre aumento da proteólise muscular, com balanço nitrogenado negativo ${ }^{21}$. Diminui-se a produção hepática de albumina, apoproteínas e transferrina, enquanto se aumenta a síntese de proteínas de fase aguda, incluindo proteína $\mathrm{C}$ reativa e fibrinogênio ${ }^{617}$.

Deficiências alimentares constituem-se em possíveis causas de subnutrição crônica e de anemia observadas em pacientes com AIDS, especialmente em países subdesenvolvidos. Entretanto, estudos realizados em diferentes contextos sócio-econômicos sugerem que a ingestão de alimentos pode estar adequada ${ }^{1020}$, condição em que as alterações do estado nutricional decorreriam de má absorção associada à diarréia, do aumento do consumo de energia ou de alterações metabólicas associadas com infecções.

A RFA pode manifestar-se por sinais e sintomas com freqüência observados em pacientes HIV-positivos, incluindo anorexia, febre e edema hipoalbuminêmico, além de anemia progressiva, com diminuição dos níveis séricos do ferro e da transferrina ${ }^{6722}$. A hipótese deste estudo foi que a anemia de pacientes com AIDS ocorre em concomitância com a RFA, situação na qual a subnutrição protéico-energética também seria mais comum. O objetivo do presente trabalho foi comparar o estado nutricional e alguns parâmetros do metabolismo do ferro em pacientes com AIDS, com ou sem RFA.

\section{CASUÍSTICA E MÉTODOS}

O trabalho foi realizado no período entre agosto de 1996 e março de 1997, nas enfermarias e ambulatórios do Hospital Escola da Faculdade de Medicina do Triângulo Mineiro, Uberaba, MG, após aprovação da Comissão de Ética em Pesquisa da Instituição. Cada um dos vinte e nove voluntários concordou, por escrito, em participar da pesquisa, que envolveu adultos com infecção pelo HIV-1, diagnosticada pelo método ELISA (enzime-linked immunosorbent assay) e confirmada pela técnica Western blot. O diagnóstico de AIDS foi realizado segundo os critérios de Caracas e do CDC Centers for Disease Control ${ }^{16}$. Foram utilizados os seguintes critérios de inclusão: 1) os pacientes deveriam estar auto e alopsiquicamente orientados; 2) ter condições físicas adequadas para realização de antropometria; 3 ) não apresentar história de diarréia recente; 4) não estar recebendo terapia nutricional enteral ou parenteral 5) não estar usando medicamentos orexígenos ou suplementos vitamínicos.

Foram registrados dados demográficos, incluindo idade, raça e sexo, além dos diagnósticos principais e medicamentos usados. O sangue, obtido para realização do hemograma e avaliação laboratorial dos níveis séricos de proteínas totais, albumina, ferro, ferritina e CTLF (capacidade total de ligação do ferro), foi colhido em veias cubitais com agulhas e seringas descartáveis, após jejum noturno de 12 horas. Os exames bioquímicos foram realizados num Automatic Chemical Analyzer, modelo Cobas Mira Plus ${ }^{\circledR}$ (Roche Diagnostic Systems, Inc - Branchburg, NJ). A proteína C reativa (PCR) foi determinada pelo teste quantitativo de látex em lâmina. Os valores de linfócitos $\mathrm{CD}_{4}$ foram determinados por citometria de fluxo e anticorpos monoclonais ${ }^{19}$.

Para determinação da creatinina urinária de 24 horas, a urina foi coletada em frascos de vidro esterilizados, aos quais foram adicionados $10 \mathrm{ml}$ de ácido clorídrico $6 \mathrm{~N}$ para cada litro de urina. $\mathrm{A}$ diurese de 24 horas foi medida em cilindros graduados e as amostras guardadas sob refrigeração até análise. As dosagens de creatinina urinária foram realizadas de acordo com o método de Clark e Thompson (1949) ${ }^{4}$. A partir 
da determinação de creatinina urinária, foi calculada sua percentagem de adequação da massa muscular ${ }^{124}$, expressa como índice de creatinina altura (ICA), conforme a fórmula: ICA = valor encontrado $(\mathrm{mg} / 24 \mathrm{~h}) \times 100 /$ peso corporal ideal $x$ creatinina ideal $(23 \mathrm{mg} / \mathrm{kg}$ para homens e $18 \mathrm{mg} / \mathrm{kg}$ para mulheres).

$A$ avaliação antropométrica foi realizada conforme padronização ${ }^{23}$. A altura foi aferida por meio de uma haste metálica graduada e o peso corporal foi medido em balança portátil com precisão de $50 \mathrm{~g}$, estando o indivíduo em pé, ereto, vestido e descalço. O comprimento do braço foi determinado com fita métrica inextensível no braço não dominante, pela distância entre o acrômio e o olécrano. No ponto médio, aferiu-se a circunferência do braço (CB, em $\mathrm{cm}$ ) e a prega cutânea tricipital (PCT, em mm), medida com plicômetro Holtainß. $\mathrm{O}$ estado nutricional foi determinado pelo índice de massa corporal, baseado no peso corporal e altura, conforme a equação (IMC = peso, kg/altura $\left.{ }^{2}, \mathrm{~m}\right)$, sendo considerados subnutridos aqueles com IMC $<18,5 \mathrm{~kg} / \mathrm{m}^{2}$ e/ou índice creatinina-altura $<70 \%{ }^{13}$. A presença da síndrome da resposta de fase aguda foi considerada quando havia infecção associada com níveis séricos de proteína $C$ reativa maiores que $7 \mathrm{mg} / \mathrm{dl}$.

Além da suplementação diária de ácido fólico (400mg/dia), todos os pacientes tomavam doses terapêuticas de zidovudina e didanosina. Nenhum deles estava recebendo inibidores de proteases. A avaliação quantitativa da ingestão alimentar foi realizada pelo método do Recordatório de 24 horas. Os alimentos ingeridos no dia anterior à entrevista foram registrados em medidas caseiras e os dados analisados por método computadorizado ${ }^{9}$, quantificando-se a ingestão diária de energia, ferro e ácido ascórbico.

As variáveis contínuas com distribuição normal foram expressas como média \pm desvio padrão; neste caso a comparação entre RFApositivos e RFA-negativos foi realizada usandose o teste $t$ de Student. O teste de Mann-Whitney foi empregado na comparação de variáveis de distribuição não-normal, que foram expressadas como mediana e faixa de variação. O teste do $\chi^{2}$ ou o teste exato de Fisher foram empregados na comparação de freqüência entre os grupos. Foram consideradas significativas probabilidades menores que 0,05 .

\section{RESULTADOS}

Não houve diferença significativa entre pacientes RFA-positivos ( $\mathrm{n}=9$ ) e RFA-negativos $(n=21)$, respectivamente, quanto à idade $(30,1 \pm 9,6$ vs $36,9 \pm 9,8$ anos) e porcentagem de indivíduos do sexo masculino (88,9 vs 90$)$ e de cor branca $(88,9$ vs 90$)$. Não houve diferença entre os grupos quanto à categoria de exposição ao HIV-1, predominantemente sexual $(56,6 \%)$ e pela via sangüínea, em usuário de droga ilícita intravenosa $(43,3 \%)$. Exceto pela maior percentagem de casos com tuberculose pulmonar no grupo RFA-positivos (44,4 vs $9,5 \%)$, não houve diferença na proporção de diagnósticos principais, incluindo toxoplasmose e criptococose cerebral $(55,5$ vs $33,3 \%)$ e candidíase oral e esofagiana $(44,4$ vs $33,3 \%)$.

A subnutrição protéico-energética ocorreu em $51,7 \%$ dos pacientes estudados, sendo mais comum (Figura 1) em pacientes RFA-positivos ( 77,8 vs $40 \%)$. O peso corporal, o índice creatininaaltura $(46,3 \pm 31,1$ vs $82,9 \pm 23,0 \%)$ e a circunferência do braço $(23,5 \pm 3,2$ vs $26,0 \pm 2,8 \mathrm{~cm})$ foram estatisticamente menores nos pacientes RFApositivos (Tabela 1). Embora estatisticamente não significativo, o índice de massa corporal foi menor nos pacientes RFA-positivos $\left(18,7 \pm 2,6 \mathrm{~kg} / \mathrm{m}^{2}\right)$, quando comparados aos RFAnegativos $\left(21,3 \pm 3,7 \mathrm{~kg} / \mathrm{m}^{2}\right)$, o mesmo ocorrendo com a prega cutânea tricipital (respectivamente 6,2; variação: 4-12 vs 6,8; variação: 3,4-29,7mm).

Pacientes RFA-positivos e RFA-negativos, respectivamente, não apresentaram diferença estatística quanto aos níveis séricos de proteínas totais (7,7; variação: $5,6-9,2$ vs 7,7 ; variação: 6,4-8,4g/dl), o mesmo ocorrendo com os níveis de albumina sérica $(4,3 \pm 0,9 \mathrm{vs} 3,7 \pm 0,9 \mathrm{~g} / \mathrm{dl})$. Também não se verificou diferença significativa quanto à contagem de leucócitos totais no sangue periférico de pacientes RFA-positivos e RFA-negativos, respectivamente $(3975 \pm 1842$ vs $4300 \pm 2198$ / células por $\left.\mathrm{mm}^{3}\right)$, linfócitos totais $(974,8$; variação entre 318,2 e 6140,3 vs 1013,2; variação entre 300 e 2297,3 células por $\mathrm{mm}^{3}$ ) e linfócitos CD4 $\left(32,7 \pm 22,5\right.$ vs $135,2 \pm 85,8$ células $\left./ \mathrm{mm}^{3}\right)$.

Os dados relativos ao hemograma, ao metabolismo do ferro e à ingestão diária de energia, ferro e ácido ascórbico estão apresentados na Tabela 1. 


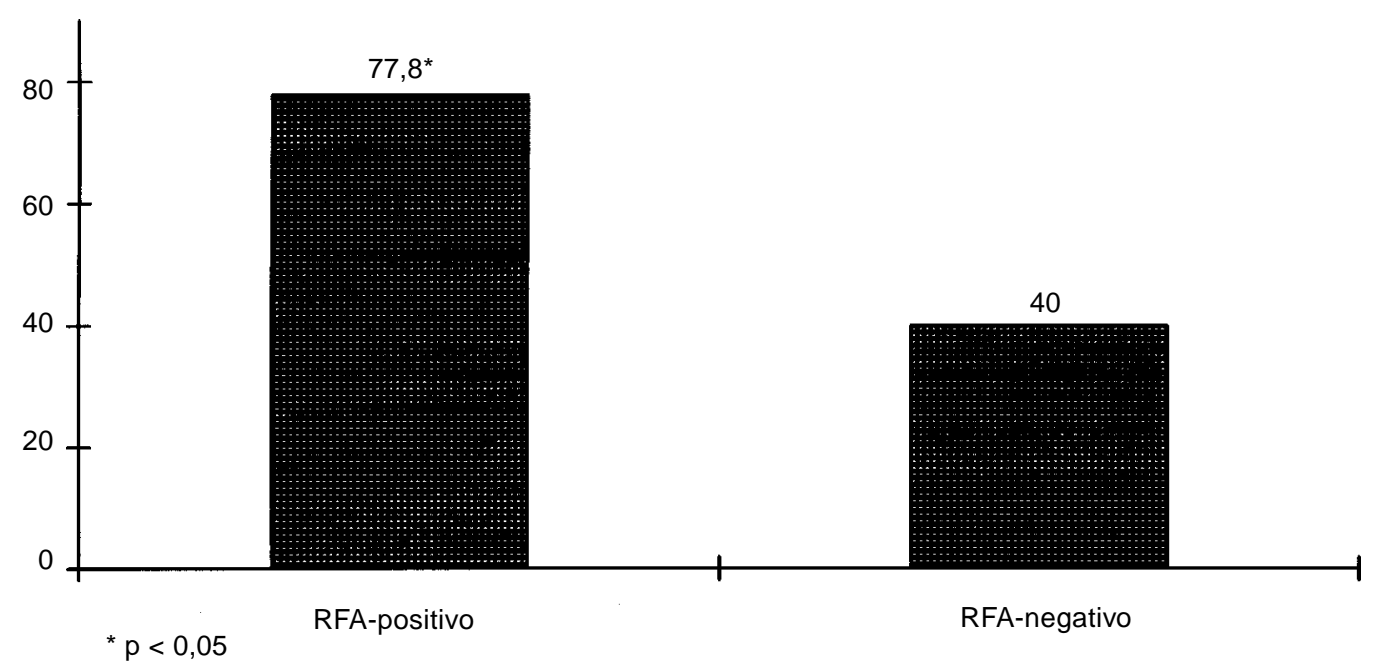

Figura 1 - Freqüência (\%) de subnutrição protéico-energética em adultos hospitalizados com AIDS e com ou sem diagnóstico de síndrome da resposta de fase aguda (RFA).

Tabela 1 - Peso corporal, dados laboratoriais do metabolismo do ferro e ingestão diária de energia, ferro e ácido ascórbico de 29 pacientes HIV-positivos, com ou sem resposta de fase aguda (RFA).

\begin{tabular}{|c|c|c|}
\hline Parâmetros & RFA-positivos & RFA-negativos \\
\hline Peso corporal $(\mathrm{kg})^{*}$ & $51,7 \pm 7,3$ & $59,2 \pm 7,3$ \\
\hline Hemácias (células $\left.\times 10^{3} / \mathrm{mm}^{3}\right)^{*}$ & $3.292 \pm 668$ & $3.839 \pm 623$ \\
\hline Hemoglobina $(\mathrm{g} / \mathrm{dl})^{*}$ & $10,5 \pm 1,8$ & $12,6 \pm 2,3$ \\
\hline Volume corpuscular médio (fl) & $97,3 \pm 8,2$ & $97,7 \pm 8,6$ \\
\hline Ferro sérico $(\mathrm{mg} / \mathrm{dl})$ & $62,9 \pm 47,3$ & $67,0 \pm 34,8$ \\
\hline $\operatorname{CTLF}(\mathrm{mg} / \mathrm{dl})^{*}$ & $165,8 \pm 110,7$ & $265,9 \pm 74,6$ \\
\hline Ferritina $(\mathrm{ng} / \mathrm{ml})^{*}$ & $568(45,3-1814)$ & $246(18,4-1577)$ \\
\hline Energia ingerida (kcal/dia) & $2184,2 \pm 879,4$ & $3363,5 \pm 1764,6$ \\
\hline Ferro ingerido (mg/dia) & $19(10-24,6)$ & $19,7(4,2-54,2)$ \\
\hline Ácido ascórbico ingerido (mg/dia) & $96(11,9-230,7)$ & $121,4(6,6-520,7)$ \\
\hline
\end{tabular}

${ }^{*} p<0,05 ;$ CTLF $=$ capacidade total de ligação do ferro

\section{DISCUSSÃO}

No presente estudo, documentou-se que anemia e subnutrição são comuns em adultos com AIDS, sendo mais freqüentes nos pacientes com a síndrome da RFA, resultados similares aos observados em indivíduos chagásicos, falecidos com a síndrome da resposta de fase aguda secundária à sepsis ou ao traumatismo grave ${ }^{8}$. Embora critérios antropométricos sejam mais precisos na definição do marasmo, em que há balanço energético negativo e desgaste progressivo da gordura corporal ${ }^{13}$, o emprego do índice creatinina-altura também permitiu documentar a menor massa muscular nos pacientes com AIDS que desenvolveram RFA.
É provável que parte da maior morbidade e mortalidade associada à AIDS esteja ligada à subnutrição protéica decorrente da resposta de fase aguda, visto que nesta situação também há diminuição do número de linfócitos e da imunocompetência celular, mudanças no padrão de secreção de anticorpos e de proteínas do sistema complemento, menor capacidade de cicatrização, balanço hídrico positivo associado à hipoalbuminemia ${ }^{15}$ e alterações eletrolíticas, incluindo hiponatremia e hipofosfatemia 6 . Embora não observados no presente estudo, a má absorção associada com a diarréia crônica e a ingestão alimentar reduzida secundária à 
anorexia também podem ser fatores importantes na patogênese da subnutrição de pacientes com AIDS e infecções oportunísticas ${ }^{10}$. É possível que o tratamento eficaz das infecções secundárias, com maior estabilidade do quadro clínico tenha contribuído para a melhora do apetite e da ingestão alimentar dos pacientes estudados.

As causas de anemia em pacientes HIV são múltiplas ${ }^{18} \mathrm{e}$ incluem os efeitos inibitórios diretos e indiretos do HIV sobre as células progenitoras (stem cells), o aumento da destruição das hemácias e a inibição da medula óssea por patógenos oportunísticos, além do efeito de agentes terapêuticos como a zidovudina. Embora os níveis de hemoglobina possam não se correlacionar com os valores de ingestão de ferro obtidos no recordatório alimentar, os resultados do presente estudo indicam que a resposta de fase aguda seria um dos fatores envolvidos na patogênese da anemia de pacientes HIVpositivos.

$\mathrm{Na}$ RFA, a anemia e a diminuição da hemoglobina e do ferro circulantes fazem parte da defesa do hospedeiro e decorrem principalmente da menor produção de hemácias e do seqüestro do ferro no fígado, nos músculos e em células do sistema fagocítico mononuclear. Os níveis séricos de ferritina aumentam porque esta proteína tem a capacidade de agregar átomos de ferro, apartando-os para o compartimento de armazenamento do ferro ${ }^{214}$, o que diminuiria a disponibilidade de ferro livre para bactérias e outros microorganismos, otimizando os sistemas bacteriostáticos e bactericidas do soro, linfa e exsudatos $^{225}$. Os dados deste estudo também estão de acordo com a literatura, que indica menores valores de hemoglobina em fases mais avançadas da infecção pelo HIV e na concomitância de infecções oportunísticas.

Limitações deste trabalho incluem a ausência de dados sobre os níveis séricos de eritropoietina e de histologia da medula óssea dos pacientes estudados. A maioria dos pacientes com graus avançados da infecção pelo HIV apresenta diminuição dos níveis de eritropoietina séricos ${ }^{3}$; sabe-se também que doses terapêuticas de zidovudina e didanosina podem provocar citopenias, o mesmo ocorrendo com a infecção da medula óssea pelo próprio HIV-1 ou por patógenos oportunísticos ${ }^{511}$. Pacientes de ambos os grupos estavam recebendo terapêutica similar, incluindo zidovudina e ácido fólico e a maioria dos casos apresentavam valores médios elevados de volume corpuscular médio, o que torna improvável um efeito preferencial destes medicamentos em pacientes RFA-positivos. Além disso, exceto pela tuberculose pulmonar, as infecções associadas ocorreram com a mesma freqüência entre RFA-positivos e RFA-negativos. Entretanto, o esclarecimento desse tópico requer estudos que documentem a resposta de fase aguda em diferentes infecções oportunísticas associadas.

Concluindo, os dados do presente estudo indicam que pacientes HIV positivos e com a síndrome da resposta de fase aguda são nutricionalmente mais comprometidos e têm anemia que parece não depender da ingestão recente de ferro. Nesse contexto, a determinação rotineira dos níveis séricos da proteína $C$ reativa poderia auxiliar o médico na escolha adequada da terapêutica, incluindo a precaução na reposição intravenosa de ferro ou sangue e numa expectativa mais realista quanto aos resultados da terapia com eritropoietina recombinante.

\section{REFERÊNCIAS BIBLIOGRÁFICAS}

1. Blackburn GL, Bistrian BR, Maini BS, Benoti P, Bothe A, Gibson G, Schlamm H, Smith MF. Nutritional and metabolic assessment of the hospitalized patient. Journal of Parenteral and Enteral Nutrition 1:11-21, 1977.

2. Bobbio-Pallavicini F, Verde G, Spriano P, Losi R, Bosatra MG, Braschi A, lotti G, Chiaranda M, Villa S. Body iron status in critically ill patients: significance of serum ferritin. Intensive Care Medicine 15:171-178, 1998.

3. Camacho J, Poveda F, Zamorano AF, Valencia ME, Vazquez JJ, Arnalich F. Serum erythropoietin levels in anaemic patients with advanced human immunodeficiency virus infection. British Journal of Haematology 82:608614, 1992.

4. Clark LC, Thompson HL. The determination of creatine and creatinine in urine. Analytical Chemistry 21:1218-1221, 1949.
5. Coyle TE. Hematologic complications of human immunodeficiency virus infection and the acquired immunodeficiency syndrome. Medical Clinics of North America 81:449-470, 1997.

6. Cunha DF, Cunha SFC, Piloto PE, Santos NP, Barros JW. Estado nutricional e resposta de fase aguda em pacientes com fratura do terço proximal do fêmur. Revista Brasileira de Ortopedia 3:321-324, 1998.

7. Cunha DF, Santos VM, Monteiro JP, Carvalho da Cunha SF. Hypophosphatemia in acute-phase response syndrome patients. Preliminary data. Mineral and Electrolyte Metabolism 24:337-340, 1998.

8. Cunha DF, Vieira CO, Silva GP, Erédia GR, Teixeira VPA. Reação de fase aguda e parasitismo na veia central da 
supra-renal em chagásicos crônicos. Revista da Sociedade Brasileira de Medicina Tropical 27:.83-86, 1994.

9. Cunha SFC, Bianchi MLP, Cunha DF, Salgado SM, Dutra de Oliveira JE. Ingestão de fibras alimentares em mulheres com constipação intestinal. Arquivos de Gastroenterologia 29:137-141, 1992.

10. Dworkin BM, Wormser GP, Axelrod F, Pierre N, Schwarz $E$, Schwartz E, Seaton T. Dietary intake in patients with acquired immunodeficiency syndrome (AIDS), patients with AIDS-related complex, and serologically positive human immunodeficiency virus patients: correlations with nutritional status. Journal of Parenteral and Enteral Nutrition 14:605-609, 1990.

11. Harris CE, Biggs JC, Concannon AJ, Dodds AJ. Peripheral blood and bone marrow findings in patients with acquired immune deficiency syndrome. Pathology 22:206-211, 1990.

12. Hecker LM, Kotler DP. Malnutrition in patients with AIDS. Nutrition Reviews 48:393-401, 1990.

13. James WP, Ferro-Luzzi A, Waterlow JC. Definition of chronic energy deficiency in adults. Report of a working party of the International Dietary Energy Consultative Group. European Journal of Clinical Nutrition 42:969-981, 1988.

14. Konijn AM. Iron metabolism in inflammation. Baillières Clinical Haematology 7:829-849, 1994.

15. McMahon MM, Bistrian BR. The physiology of nutritional assessment and therapy in protein-calorie malnutrition. Disease-a-Month 36:373-417, 1990.

16. Ministério da Saúde. Programa Nacional de Doenças Sexualmente Transmissíveis/AIDS. Revisão da definição nacional do caso de AIDS em adultos. Brasília, p.2-5, 1992.

17. Moldawer LL, Copeland EM. Proinflammatory cytokines, nutritional support, and the cachexia syndrome: interactions and therapeutic options. Cancer 79:18281839, 1997.

18. Moses A, Nelson J, Bagby GC Jr. The influence of human immunodeficiency virus-1 on hematopoiesis. Blood 91:1479-1495, 1998.

19. Parker JW, Adelsberg B, Azen SP, Boone D, Fletcher MA, Gyrset GF, Hassett J, Kaplan J, Niland JC. Leukocyte immunophenotyping by flow cytometry in a multisite study: standardization, quality control and normal values in the transfusion safety study. Clinical Immunology and Immunopathology 55:187-220, 1990.

20. Sharkey SJ, Sharkey KA, Sutherland LR, Church DL. GI/ HIV-study group. Nutritional status and food intake in human immunodeficiency virus infection. Journal of Acquired Immunodeficiency Syndrome and Human Retrovirology 5:1091-1098, 1992.

21. Sharpstone DR, Ross HM, Gazzard BG. The metabolic response to opportunistic infections in AIDS. AIDS 10:1529-1533, 1996.

22. Van Iperen CE, Kraaijenhagen RJ, Biesma DH, Beguin Y, Marx JJ, Van de Wiel A. Iron metabolism and erythropoiesis after surgery. British Journal of Surgery 85:41-45, 1998.

23. Vannucchi H, Marchini JS, dos Santos, JE, Dutra de Oliveira JE. Avaliação antropométrica e bioquímica do estado nutricional. Medicina, Ribeirão Preto 17:17-28, 1984.

24. Walser M. Creatinine excretion as a measure of protein nutrition in adults of varying age. Journal of Parenteral and Enteral Nutrition 11(supl):73S-78S, 1987.

25. Ward CG, Bullen JJ, Rogers HJ. Iron and infection: new developments and their implications. Journal of Trauma 41:356-364, 1996. 